\title{
Pharmacodynamic analysis and concentration mapping for efficient delivery through the FUS-induced BBB opening in non-human primates in vivo
}

\author{
Gesthimani Samiotaki", Maria Eleni (Marilena) Karakatsani, Shih-Ying Wu, Amanda Marie Buch, Elisa Konofagou
}

From Current and Future Applications of Focused Ultrasound 2014. 4th International Symposium

Washington, D.C, USA. 12-16 October 2014

\section{Background/introduction}

FUS in conjunction with systemically administered microbubbles has been previously shown to open the Blood-Brain Barrier (BBB) locally, non-invasively and reversibly in non-human primates. However, a trans$\mathrm{BBB}$ pharmacodynamic analysis has not been performed as of yet. The objective of this study was to perform such an analysis, i.e. permeability, relaxivity and gadolinium concentration mapping, of the NHP brain in vivo in order to further investigate the effect of FUS, and its dependence on the acoustic parameters used for safe and efficient drug-delivery as well as the gray $v s$. white matter occurrence.

\section{Methods}

Two brain structures, the caudate and the putamen, were targeted in three rhesus macaques using FUS (center frequency: $500 \mathrm{kHz}$; pulse length: 5,000 cycles; PRF: $2 \mathrm{~Hz}$; sonication duration: $120 \mathrm{~s}$; peak negative pressure: $300-500 \mathrm{kPa}$ ) immediately after the IV administration of monodisperse bubbles (diameter: 4-5 $\mu \mathrm{m}, 2.5^{*} 108 \# / \mathrm{kg}$ ). Following sonication, the macaques were placed in a $3 \mathrm{~T}$ MR scanner (Philips Medical System, Andover, MA, USA). Five pre-contrast 3D Spoiled Gradient Echo (SPGR) images (TR/TE: 10/4ms, FA: 5o-35o, NEX: 3, matrix: 256x256, resolution: 1x1x1 mm3) were acquired and used for variable flip angle *VFA) based T1 relaxivity mapping. Subsequently, Dynamic Contrast Enhanced (DCE) imaging was performed, with the acquisition of 90 dynamic T1-weighted 3D repetitions (TR/TE: 4.2/1.7 ms; matrix: 256x256, resolution $1 \times 1 \times 2 \mathrm{~mm} 3)$. The data of the

Columbia University, New York, New York, United States
DCE were processed off-line using a customized Matlabbased algorithm and fitted to the General Kinetic Model using the Patlak method to generate permeability maps.

Quantitative permeability changes (Ktrans) and the volume of $\mathrm{BBB}$ opening after excluding the vasculature were obtained based on the $\mathrm{T} 1$ relaxivity maps. The areas of gray and white matter where BBB opening was induced were also determined, since they have distinctive characteristic relaxivity times. Gadolinium concentration [Gd] maps were then calculated from the T1, pre map before MR-CA injection and the T1, post maps after MR-CA injection using the following equation: $[\mathrm{Gd}]=1$ / r_Gd (1/T_(1, post) $-1 / \mathrm{T}_{-}(1$, pre $\left.)\right)$. Vasculature and CSF were excluded from the opening volume based on their T1 relaxivity which was measured to be above $1400 \mathrm{~ms}$.

\section{Results and conclusions}

The volume of opening increased from $92 \pm 10 \mathrm{~mm} 3$ to $262 \pm 34 \mathrm{~mm} 3$ with a pressure increase from $300 \mathrm{kPa}$ to $500 \mathrm{kPa}$ increased. The average permeability was increased from $1.0531 \pm 0.0761^{*} 10-4 \mathrm{~s}-1$ to $1.863 \pm$ $0.132 * 10-4 \mathrm{~s}-1$ with the same pressure increase. When targeting the putamen, an average of $95 \%$ of the BBB opening regions was contained in the grey matter ( $\mathrm{T} 1$ relaxivity range: $1001-1400 \mathrm{~ms}$ ), while when targeting the caudate $87 \%$ of the BBB-opened regions were in the gray matter and the rest in the white (T1 relaxivity range: $600-1000 \mathrm{~ms}$ ). No edema or hemorrhage was detected in any of the cases studied. FUS-induced drug delivery efficiency was measured in vivo for the first time and increased with the acoustic pressure used; the amount of gadolinium in the opened BBB area increased from $10 \mu \mathrm{g}$ to $20 \mu \mathrm{g}$ on average when pressure increased 


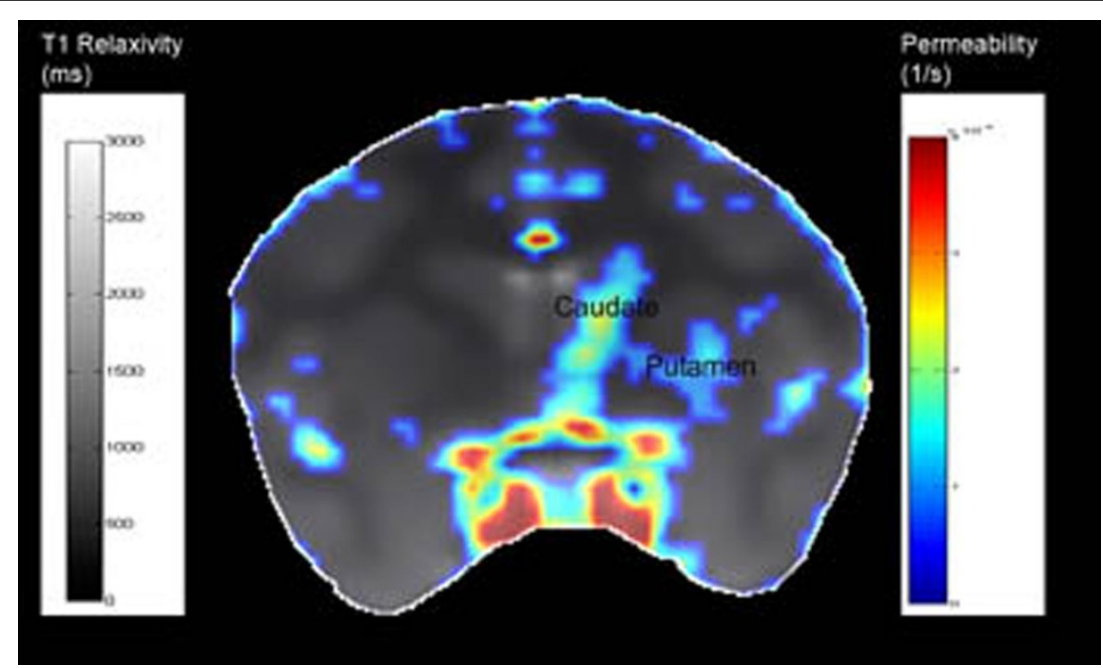

Figure $1 \mathrm{~T} 1$ map overlaid with permeability map in a coronal view

from 300 to $600 \mathrm{kPa}$. This type of analysis as performed in this study may prove critical for clinical applications.

\section{Acknowledgements (Funding)}

The authors wish to acknolwedge Matthew Downs and Carlos Sierra Sanchez for their input and help. Funding: National Institutes of Health (R01

EB009041 \& R01AG038961), Wallas H. Coulter Foundation, Focused

Ultrasound Foundation.

Published: 30 June 2015

doi:10.1186/2050-5736-3-S1-P33

Cite this article as: Samiotaki et al:: Pharmacodynamic analysis and

concentration mapping for efficient delivery through the FUS-induced

BBB opening in non-human primates in vivo. Journal of Therapeutic

Ultrasound 2015 3(Suppl 1):P33.

\section{Submit your next manuscript to BioMed Central} and take full advantage of:

- Convenient online submission

- Thorough peer review

- No space constraints or color figure charges

- Immediate publication on acceptance

- Inclusion in PubMed, CAS, Scopus and Google Scholar

- Research which is freely available for redistribution 